\title{
Long-term effects and psychological adjustment: study protocol of a large register-based study on quality of life among survivors of hematological malignancies
}

Peter Esser ${ }^{*}$, Katharina Kuba, Heide Götze and Anja Mehnert

\begin{abstract}
Background: Both incidence and survival rates of hematological cancers are increasing, leading to a growing number of survivors with specific late and long-term effects. However, relevant research in physical, psychological and social aspects of quality of life is scarce. Existing literature shows that a considerable number of cancer survivors report a relatively high quality of life despite a variety of adverse and persistent symptoms. To date, the reasons for this phenomenon as well as moderating and mediating factors are widely unknown. Given these research gaps, we aim to investigate the different domains of quality of life among long-term survivors of hematological cancers and to identify factors predicting high quality of life.

Methods/Design: This is a large cross-sectional study among hematological cancer survivors at a minimum of 3 years after diagnosis. We will collect 1000 survivors completing a set of self-report-questionnaires encompassing physical, psychological and social domains of quality of life. Participants are clustered in groups according to time since diagnosis and compared with each other. Furthermore, survivors will be compared with the general population. Factors predicting high quality of life will be identified via multiple regression analyses and structure equation modeling.

Discussion: Our study will help to inform health care providers about the specific long-term burden among survivors with hematological malignancies. Identification of factors predicting high quality of life will help to develop adequate intervention strategies to enhance well-being in hematological cancer survivors. Our methodological advantages including the large sample as well as the assessment of different domains of quality of life will ensure novel and robust results. A limitation of the study is the cross-sectional design.
\end{abstract}

Keywords: Hematological malignancies, Long-term effects, Late effects, Survivorship, Health and wellbeing, Psychological adjustment

\footnotetext{
* Correspondence: peter.esser@medizin.uni-leipzig.de

Department of Medical Psychology and Medical Sociology, University

Medical Center Leipzig, Philipp-Rosenthal-Str. 55, 04103 Leipzig, Germany
} 


\section{Background}

Fortunately, survival rates among hematological cancer patients are considerably improving $[1,2]$. In a Europewide study among 6.7 million cancer patients, Hodgkin's and non-Hodgkin-Lymphomas were among those types with the highest improvement in survival rates [3]. Given the rising incidence of hematological cancers in the industrialized countries [4], the health care systems are confronted with a growing population strained by specific adverse late or long-term effects.

The first step in developing adequate intervention strategies and survivorship care plans is to assess the specific medical and psychosocial needs of cancer survivors [5]. However, compared to other cancer types, only few studies exist assessing quality of life (QoL) in hematological cancer patients [6-8]. This is problematic, as hematological cancer types differ from other cancer sites in many aspects. Some types are classified to be chronic $[9,10]$, while others have a high risk for relapse, with rates up to $92 \%$ [11]. Moreover, the risk for developing a second malignancy is elevated up to 20 years after treatment $[12,13]$. As many hematological cancer types are systemic, therapy is often more toxic and invasive compared to other malignancies. A treatment primarily used among this group is hematopoietic stem cell transplantation (HSCT) [14], which negatively affects a variety symptoms up to 10 years after HSCT [14-20]. All these features negatively impact the patients' lives in many aspects. For example, hematological cancer patients have a three-fold increased risk for quitting work due to cancer when compared to colorectal cancer survivors [21].

Regarding change in QoL over time, some studies found time since diagnosis to have an effect on QoL $[22,23]$, while others did not $[8,24,25]$. Paradox seems the result by Miltény et al. [26] showing that survivors of Hodgkin's Lymphoma with more than 20 years after treatment had a significant higher level in fatigue than patients under current treatment. Another finding is that different QoL domains seem to resolve or occur in specific time frames. For example, Syrjala et al. [19] showed that physical impairment among leukemia and lymphoma patients (baseline $n=319)$ treated with HSCT improves more rapidly than impairments in the psychological or psycho-social domains.

When comparing long-term survivors with non-cancer control groups, Wettergren et al. [27] revealed that QoL among survivors of Hodgkin's Lymphoma $(N=121)$ at a mean of 14 years after diagnosis did not significantly differ from a control group. In another study among hematological cancer patients 10 years after HSCT, survivors $(N=137)$ reported more medical problems than controls, but did not differ in psychological health [18]. Two studies showed better physical functioning [22] and lower bodily pain [23] in Hodgkin's Lymphoma survivors 10-15 years after transplantation than a comparison group from the general population. This surprising fact is supported by qualitative data based on cancer survivors between 6 and 18 years after HSCT, indicating that despite several impairments, the majority see themselves as relatively well [28]. Taken together, previous research is inconclusive and mostly based on HSCT patients, which reduces the generalizability of the findings.

Furthermore, the aforementioned results pose not only the question of whether, to what extent and when hematological cancer survivors experience late and longterm effects, but also how they adapt to them. In this context, Zebrack et al. [29] suggested that QoL might be partially explained by the cognitive frame or the meaning they attribute to the cancer experience. Another study by Lim et al. [30] among long-term survivors of leukemia and lymphoma ( $N=53 ; \geq 10$ years after diagnosis) identified non-medical predictors of QoL such as satisfaction with social support or use of supportive care services. Other studies among cancer patients discussed the meaning of coping styles, self-efficacy or global appraisal of stress in predicting better adaptation and QoL [31-33]. Concepts linking clinical variables with QoL mediated by personality characteristics are also discussed outside the oncology setting [34]. More research is needed to identify factors influencing adjustment of long-term cancer survivors [29], which in turn could help to enhance QoL in cancer patients with adequate interventions strategies.

\section{Objectives}

Taking into account research gaps, inconclusive results and highly selected samples in previous studies, our primary aim is to investigate long-term effects of physical, psychological and social domains of QoL among a large sample of hematological cancer survivors, starting from 3 years after diagnosis. This approach will allow us to present various dimensions of QoL at different phases following a hematological cancer diagnosis. Large comparison data from the general population will help to better estimate the burden of those patients. Beyond this descriptive scope, our second aim is to look for nonmedical and non-physical factors moderating or mediating the relationship between medical/physical burden and subjective well-being. This will help to identify and to therapeutically address features that are predictive for high QoL despite adverse and long-standing consequences.

\section{Methods/Design}

Study design

This is a large cross-sectional study among hematological cancer survivors. Owing to chronicity as well as long treatment and rehabilitation periods among respective patients, we chose a minimum period of 3 years after primary diagnosis. All participants will fulfill a set of selfreport-questionnaires, either paper pencil or online. 


\section{Study participants}

We will collect data of at least 1000 patients with malignant neoplasms of lymphoid, hematopoietic and related tissue (ICD-10: C81-C96). Further inclusion criteria are (i) minimum period of 3 years after diagnosis, (ii) minimum age of 18 years at time of diagnosis, (iii) maximum age of 85 at time of assessment, (iv) sufficient knowledge of the German language, (v) physical, psychological and cognitive ability for study participation and (vi) written informed consent. We seek to end with five relatively equal groups $(n=200$ each) clustered in $3-5$ years, $6-8$ years, 9-11 years and $12-14$ years and $\geq 15$ years after first diagnosis.

\section{Recruitment}

Collaborations with the Clinical Cancer Registry at the Cancer Center Leipzig and the Epidemiologic Cancer Registry of Schleswig-Holstein ensure access to contact information for eligible patients in two cancer registries. Trained personnel in the two institutions (the city of Leipzig and the federal state of Schleswig-Holstein) extract patients who both gave general permission to be contacted for research projects and fulfill our inclusion criteria. Eligible patients are then contacted by sending them a package containing (i) a letter in which they are asked to participate in the study (ii) a flyer with important study information, (iii) the questionnaire, (iv) a declaration of consent and (v) a stamped envelope. Participants fill in the questionnaire and the declaration of consent and send these documents back to the coordinating study center. Alternatively, patients can participate online by using the software LimeSurvey [35]. Patients who do not respond within the next weeks are reminded. In case they do not wish to participate, they are asked to report their reason for non-participation on a form enclosed in the reminding package.
According to the tumor center of Leipzig, around 60\% of all extracted (i.e. eligible) survivors will be deceased or cannot reached due to organizational reasons (e.g. change of name by marriage, move). To ensure our target sample size, we also collect participants from other sources, including social media, patient congresses, established doctors and self-help groups. An overview of our recruitment procedure and sample composition is given in Fig. 1.

\section{Bias control}

Responders and non-responders will be analyzed in terms of important sociodemographic (such as age and gender) and medical characteristics (such as type of diagnosis and time since diagnosis). Significant group differences will be taken into account in both statistical models and interpretation of the findings. Furthermore, reported reasons for non-participation, e.g. organizational reasons or physical and psychological burden, will be evaluated to estimate other possible sample biases.

Finally, participants are assigned to two major groups, i.e. 'cancer registry' vs. 'other sources'. Respective bias control will be ensured by either separate analyses or by including a group variable in multivariate analyses.

\section{Minimum sample size}

The target sample size is based on the minimum number of patients in each of the five subsamples $(3-5$ years, 6-8 years, 9-11 years, $12-14$ years and $\geq 15$ years) that is necessary to identify predictors for high QoL.

As a first step, we estimated the expected amount of patients with relatively high QoL. For this purpose, we used a previous study among hematological cancer patients at a mean of 7 years after diagnosis (for further information see T3-sample in Esser et al. [36]). In detail, we calculated the percentage of patients with a QoLscore of the EORTC-QLQ-C30 [37] not less than one

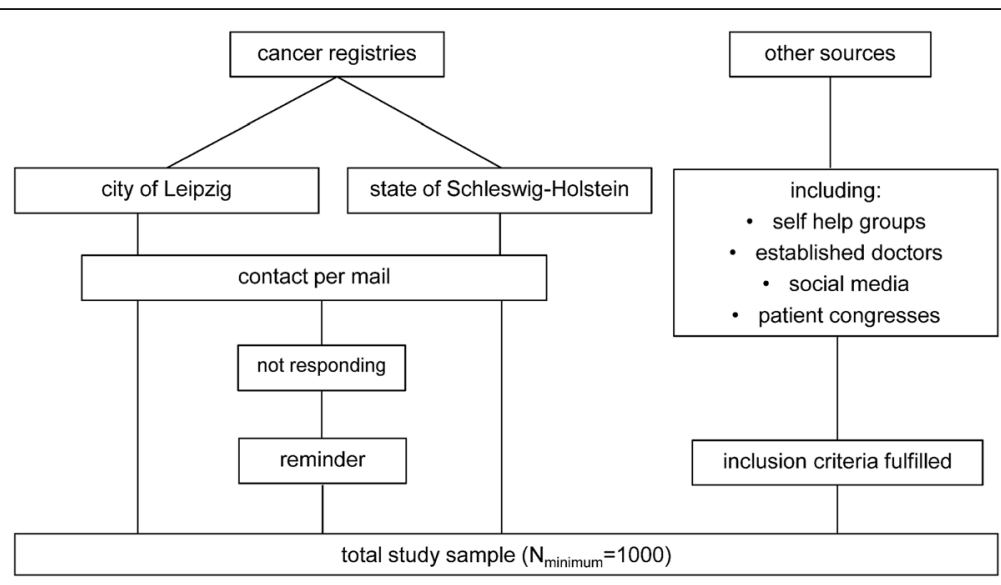

Fig. 1 Recruitment procedure and sample composition 
standard deviation below the German norm values [38]. This applied to around $60 \%$ of the patients. As a second step, we calculated the required sample size which is necessary to apply appropriate multiple regression analyses. For this a priori-computation, we applied G*Power 3.1 [39], using 'Fixed Model, $\mathrm{R}^{2}$ increase' [40]: Given a test power of $80 \%$ and an alpha-level of .05 , a sample size of 114 is needed to determine an effect of $\mathrm{f}^{2}=0.10$ in multiple regression analyses that allow to test for three potential predictors when taking into account the three most important control variables (age, gender and diagnosis). Given that around $60 \%$ of the patients show high QoL and therefore can be used in such analyses, we need subsamples of $n=200$ to ensure a minimum sample of $n=114$ to apply appropriate multiple regression analyses. Consequently, the minimum total sample size was set at $N=5^{*} 200=1000$.

\section{Comparison groups}

To estimate the burden among the cancer survivors, we compare their results with norm values. Thanks to representative surveys organized by our institution with the assistance of a demographic consulting company (USUMA, Berlin, Germany), we have access to data sets containing large, nationwide and randomly selected samples among the general population. In detail, data is available for the EORTC-QLQ-C30 $(N=2448)$ [38], FLZ $^{\mathrm{M}}(N=5036)$ [41], PHQ-9 $(N=5018)$ [42], GAD-7 $(N=5030)$ [43], NCCN Distress Thermometer $(N=2437$; previously unpublished), F-SozU $(N=2507)$ [44] and PFB-K $(N=1390)$ [45].

\section{Measurements}

The questionnaire was developed after extensive literature research and interviews with patients and experts (hematologists/oncologists). Instruments can be loosely divided in (i) sociodemographic and medical information, (ii) QoL in its different domains and (iii) premorbid/personality traits. In Table 1 , every instrument is assigned to its respective domain. Below, detailed description can be found in order of assessment.

\section{Sociodemographic and medical information}

Relevant patient characteristics including gender, age, diagnosis according to ICD-10, date of diagnosis, types of therapy and previous cancers are obtained from the cancer registries, but also assessed in the questionnaire. Furthermore, patients are asked to report on disease status and complications in the course of the disease, partnership, children, living conditions, socioeconomic and job status as well as religiosity.

\section{Quality of life (EORTC-QLQ-C30)}

The European Organization for Research and Treatment of Cancer Quality of Life Questionnaire (EORTC-QLQ-C30)
[37] is well-established across cancer sites and has been validated in German [46]. It contains 30 items, of which 28 are rated on a four-point Likert scale ranging from 'not at all' to 'very much' and can be clustered/assigned to five functioning scales (physical, role, cognitive, emotional and social), three symptom scales (fatigue, nausea, pain) and six one-item scales (dyspnea, sleeping problems, loos of appetite, constipation, diarrhea, financial problems). Additionally, general health and global QoL are rated on a seven-point Likert scale ranging from 'very poor' to 'excellent'.

\section{Satisfaction with life ( $F L Z^{M}$ - General Life Satisfaction)}

The Questionnaire on Life Satisfaction $\left(\mathrm{FLZ}^{\mathrm{M}}\right)$ is developed and validated in German [47] and consists of two modules assessing general life satisfaction and satisfaction with health. For our study, we use the first module assessing general satisfaction with life, including health, income/financial security, occupation/work, housing/living conditions, family life/children, partner relationship/ sexuality, friends/acquaintances and leisure time/hobbies. Each participant rates the subjective importance of each of these areas and, subsequently, the satisfaction with the respective domains. All items are rated on a five-point Likert scale ranging from 'not important/ unsatisfied' to 'extremely important/very satisfied'.

\section{Affectivity (PANAS)}

The Positive and Negative Affect Schedule (PANAS) [48] is validated in German [49] and contains 20 items assessing rather positive (active, interested, excited, strong, inspired, enthusiastic, proud, alert, determined, attentive) and rather negative emotions (distressed, upset, guilty, scared, hostile, irritable, ashamed, nervous, jittery, afraid). Participants are asked to rate how they feel in general, using a five-point Likert scale ranging from 'not at all/very slightly' to 'extremely'.

\section{Depressive (PHQ-9) and general anxiety disorder (GAD-7) symptomatology}

The Patient Health Questionnaire (PHQ) [50] is validated in German [51] and assesses psychiatric disorders according to the DSM-IV criteria. For our study, we use the modules for depressive (PHQ-9; e.g. "little interest or pleasure in doing things') and general anxiety disorder (GAD-7; e.g. 'trouble relaxing') symptomatology. The frequency of respective symptoms within the last 2 weeks is rated on a four-point Likert scale ranging from 'not at all' to 'almost every day'. At the end of each module, we placed the overall item of the PHQ assessing difficulties in work, at home or in social context which can be attributed to one or more problems checked in the list. These two items are rated on a four-point scale ranging from 'not difficult at all' to 'extremely difficult'. 
Table 1 Overview and categorization of instruments applied in the questionnaire

\begin{tabular}{|c|c|c|}
\hline Domain & Issue & Measures \\
\hline \multirow[t]{2}{*}{ Patient characteristics } & Sociodemographic & Internally developed \\
\hline & Medical & Internally developed \\
\hline \multicolumn{3}{|l|}{ Quality of life } \\
\hline \multirow[t]{6}{*}{ Physical } & Symptoms; physical and cognitive functioning & EORTC-QLQ-C30 [37] \\
\hline & Cancer-related fatigue & BFI [55] \\
\hline & Cognitive functioning & AFI [68] \\
\hline & Comorbidity & Comorbidity Index [76] \\
\hline & Care level and disability & internally developed \\
\hline & Late/long-term effects & internally developed \\
\hline \multirow[t]{7}{*}{ Psychological } & Emotional functioning & EORTC-QLQ-C30 [37] \\
\hline & General satisfaction & $\mathrm{FLZ}^{\mathrm{M}}[47]$ \\
\hline & Depressive symptoms & PHQ-9 [50] \\
\hline & Anxiety symptoms & GAD-7 [50] \\
\hline & General distress & NCCN Distress [52] Thermometer [52] \\
\hline & Fear of progression & FoP-Q [54] \\
\hline & Late/long-term effects & internally developed \\
\hline \multirow[t]{8}{*}{ Social } & Role and social functioning; financial difficulties & EORTC-QLQ-C30 [37] \\
\hline & Social and medical care need & SCNS-SF34 [70] \\
\hline & Social support & F-SozU [44] \\
\hline & Use of/satisfaction with social care & internally developed \\
\hline & Use of/satisfaction with medical care & internally developed \\
\hline & Employment and work ability/conditions & WAI [72]; internally developed \\
\hline & Partnership, sexuality and fertility & PFB-K [45]; Geue et al. [75]; internally developed \\
\hline & Late/long-term effects & internally developed \\
\hline \multirow[t]{7}{*}{ Premorbid/Personality Traits } & Affectivity & PANAS [48] \\
\hline & Coping styles & UCL-SF [57] \\
\hline & Psychological flexibility & AAQ-II [60] \\
\hline & Illness centrality & Wiebe et al. [63]; Helgeson et al. [63, 64] \\
\hline & Changes in Self Concept & internally developed \\
\hline & Health locus of control & MHLC [65] \\
\hline & Health behavior & $\begin{array}{l}\text { FEG [66]; report of Health Monitoring [67]; } \\
\text { internally developed }\end{array}$ \\
\hline
\end{tabular}

Note: EORTC-QLQ-C30 and questions on late/long-term effects are assigned to all QoL domains due to multidimensionality/open response format

\section{General distress (NCCN distress thermometer)}

The distress thermometer is a screener for general distress in cancer patients [52] and is validated in German [53]. The instrument consists of a single-item visual analogue scale ranging from 0 (no distress) to 10 (extremely distressed). A score of 5 or higher is interpreted as clinically significant.

\section{Fear of progression (FoP-Q)}

The Fear of Progression Questionnaire (FoP-Q) is developed and validated in German [54] and applicable for chronically ill patients. It encompasses affective reactions, partnership/family, work, loss of autonomy and coping.
Since the four latter dimensions are assessed in other parts of our study, we restrict to affective reactions (e.g. 'all types of little aches and pains make me anxious'). We further added two items, assessing the fear of cancer recurrence and late/long-term effects. All items are rated on a five-point Likert scale ranging from 'never' to 'very often'.

\section{Fatigue (BFI)}

The Brief Fatigue Inventory (BFI) [55] is validated in German [56] and assesses fatigue in clinical populations. It first asks if the patient has felt unusually tired or fatigued in the last week. Patients then rate both the 
intensity of fatigue (at the moment, on average, strongest in the last $24 \mathrm{~h}$ ) and its impact on general activity, mood, walking ability, normal work, relations with others and enjoyment of life. Items can be rated on a ten-point scale ranging from 0 (no fatigue/does not interfere) to 10 (as bad as you can imagine/completely interferes).

\section{Coping styles (UCL-SF)}

The Utrecht Coping List [57] measures how patients deal with stressful issues. We use a validated German abbreviation of this instrument [58], which has been applied in various populations $[58,59]$. Its 23 items assess six dimensions, i.e. active problem solving, palliative behavior, avoidance behavior, search for social support, depressive reactions and comforting cognitions. Items can be rated on a four-point Likert scale ranging from 'never or seldom' to 'very often'.

\section{Psychological flexibility (AAQ-II)}

Psychological flexibility was measured with the Acceptance and Action Questionnaire (AAQ-II) [60], which is translated and validated in German [61] and contains 7 items which can be rated on a seven-point Likert scale ranging from 'never true' to 'always true'.

\section{IIIness centrality}

Illness centrality measures the extent to which the cancer is central to a person's identity. The construct is assessed based on questions originally developed by Wiebe et al. [62], which were further expanded and adapted for cancer patients [63, 64]. Patients are asked to answer 4 items ('Being a cancer survivor is an important part of who I am,' I think of being a cancer survivor when I think of who I am,' 'Having had cancer is a small part of my life,' 'I think a lot about having survived cancer') on a six-point Likert scale ranging from 'not at all true' to 'completely true'.

\section{Changes in self-concept}

To assess changes in concepts of the self after having had cancer, patients are asked to three times fill in blanks of the sentence 'I am a person because I had cancer.' Answers will be analyzed qualitatively.

\section{Multidimensional health locus of control (MHLC, Form A)}

The validated Multidimensional Health Locus of Control (MHLC) [65] assesses the beliefs about one's ability to control and to influence his or her own health. It is structured in three dimensions, i.e. internal, powerful others and chance. Out of two equal forms, we chose form A. It contains 18 items (e.g. 'When I get sick, I am to blame') that can be rated on a six-point Likert scale ranging from 'strongly disagree' to 'strongly agree'. We translated this questionnaire into German.

\section{Health behavior}

Patients are asked about their drinking and smoking habits/history, physical exercise, relaxation techniques, regular intake of medicaments as well as weight and height (for calculating the BMI). The questions are loosely based on the German Questionnaire for the Assessment of Health Behavior (FEG) [66] and a report of the Federal Health Monitoring of Germany [67]. Most items can be rated on four-point Likert scales from 'never' to 'daily', others have to be affirmed and further specified (e.g. whether he/she smokes and if yes, how much).

\section{Cognitive functioning (AFI)}

The validated Attentional Function Index (AFI) [68] assesses cognitive functioning in common daily life activities focusing on attention and working memory. We translated this questionnaire into German. The first 9 items assess executive functioning (e.g. goal formulation, monitoring effective performance). The last 4 items measure behavioral and affective responses which go along with potential impairments in the executive functioning domains. All items can be rated on a visual analogue scale ranging from 'not at all' to 'extremely well/a great deal'.

\section{Social support (F-SozU)}

The Social Support Questionnaire (F-SozU) [69] is developed in German and assesses perceived or anticipated social support. For our study, we use the validated short version (F-SozU K14) [44], containing 14 items. Items are rated on a five-point Likert scale ranging from 'not true' to 'exactly true'.

\section{Social and medical care need}

The Supportive Care Needs Survey (SCNS-SF34) [70] assesses perceived needs in various domains and was validated in German [71]. To avoid redundancy, we extracted only those items which were not covered in other parts of the study, i.e. 'Physical and daily living needs' and 'Psychological Needs'. We also added an item directly assessing the care need for physical problems. All items are rated on a four-point scale ranging from 'no need' to 'high need'.

\section{Use and satisfaction with social care}

We use a module developed in our department, assessing whether the patient received support within the last month by either general practitioner/ward physician, nursing service, social workers, psychologist/psychotherapist, pastor/priest, self-help group, internet forum, relatives, friends or by any other source. In a second step, 
the patient rates the usefulness of the support on a fivepoint scale ranging from 'not at all' to 'very helpful'.

\section{Satisfaction with medical care}

We ask the patients to evaluate the medical and psychosocial care received in the acute phase as well as in the after-care and whether they felt that physicians did take their concerns about side effects and late/ long-term effects seriously. Questions can be rated on a seven-point Likert scale from 'very dissatisfied' to 'very satisfied'.

\section{Employment and work ability/conditions}

We assess whether patients were employed at the time of diagnosis, whether they received rehabilitation or retraining and whether, how and to what extent they went back to work. Work ability/conditions are measured with adapted questions of the Work Ability Index [72], which was translated in German [73]. In detail, we assess work ability at the moment compared to the best work ability ever reached, sickness leave, the type of work (physical vs. mental) and the ability to work in each of the domains.

\section{Partnership, sexuality and fertility}

Satisfaction with partnership is assessed with item 10 of the short form of the German Questionnaire for diagnostic of partnership [74], called PFB-K [45]. Patients are further asked to estimate their satisfaction with their attractiveness and sexual life, perceived impairment in sexual joy by either physical or mental strain and what development they perceive compared to pre-diagnosis. The items are rated on five-point scales ranging from 'extremely dissatisfied/never/much worse' to 'extremely satisfied/always/much better'. Items concerning fertility (completion of family planning at time of diagnosis, talks about fertility issues with the oncologist, impairment of fertility due to the cancer and its treatment) were taken from another cancer survivor study [75].

\section{Comorbidity}

We translated and adapted a validated comorbidity assessment instrument [76]. This questionnaire assesses if a patient has a certain condition and if yes, whether it interferes with his or her daily activities, ranging on a five-point scale from 'not at all' to 'a lot'. To avoid redundancy, we summarized similar items (e.g. 'coronary heart disease' and 'congestive heart failure' was summarized to 'heart diseases'). Furthermore, we added comorbidities which are typical for the hematological cancers and respective treatments, such as mucosal issues, liver disease, anemia and skin problems. We also assess occurrence of any psychiatric disorder at the moment and pre-diagnosis.

\section{Care level and disability}

We assess the occurrence of care need and disability and the official levels of disabilities.

\section{Late and long-term effects}

Finally, patients are directly asked to estimate whether and what conditions they attribute to the disease or treatment and how they are affected by those effects, ranging on five-point scale from 'not straining at all' to 'very straining'.

\section{Statistical analyses}

To investigated QoL over time, we will cluster the participants in groups with respect to the years since diagnosis and compare their means in relevant outcomes, e.g. via t-tests or chi-square tests. Those groups are then further compared with the general population. Effect sizes will be calculated to estimate the magnitude of significant effects. All analyses will be controlled for important variables such as gender, age and diagnosis.

For our aim to identify factors predicting patients to show relatively high QoL, we will apply multiple regression analyses. For more complex hypotheses, e.g. on moderating or mediating factors, we will apply structure equation modeling.

Additionally, our sample size and comprehensive assessment enables the application of confirmatory factor analyses and investigation of convergent/discriminant validity. Therefore, we will validate our German translations of the AFI [68] and the MHLC [65]. Furthermore, we will compare the patients from the cancer registry with the patients recruited from other sources. Such an investigation will be of great importance in interpreting results of the growing number of research based exclusively on patients recruited via social media.

\section{Discussion}

To date, long-term data on QoL of hematological cancer patients is very scarce and mostly based on HSCT patients, thereby limiting generalizability of results. We conduct a relevant study featuring several methodological advantages ensuring novel results. First, we use a very large dataset, enabling us to stratify in well-defined groups with respect to time since diagnosis and thus to investigate QoL including physical, psychological and social aspects at different phases post-diagnosis. Second, access to large data sets of the general population in the most important outcomes will help to extract control groups perfectly matched by age and gender. Third, patient recruitment from two cancer registries in different parts of Germany improves generalizability. Fourth, the registries ensure correct information in the most important medical and sociodemographic variables and additionally allow for responder analyses. Finally, the 
sample size allows for applying methods to detect underlying processes that predict QoL. A limitation of the study is the cross-sectional design.

Taken together, our study will help to inform health care providers about the specific long-term burden among survivors with hematological malignancies and to develop adequate intervention strategies in order to heighten QoL in this specific patient group.

\section{Acknowledgements}

We acknowledge support from the German Research Foundation (DFG) and Universität Leipzig within the program of Open Access Publishing.

\section{Funding}

The study is funded by grants from the German foundation Deutsche José Carreras Leukämie-Stiftung (grant number: DJCLS R 14/18) and sponsored by the Department of Medical Psychology and Medical Sociology at the University Medical Center of Leipzig. The funding and sponsoring sources are not involved in any stage of the research process.

\section{Availability of data and materials}

The datasets used and/or analysed during the current study are available from the corresponding author on reasonable request.

\section{Authors' contributions}

Conception and design: PE, KK, HG, AM. Drafting the manuscript/revising it critically: PE, KK, HG, AM. Final approval of the version to be published: PE, KK, HG, AM. To be accountable for all aspects of the work: PE, KK, HG, AM. All authors read and approved the final manuscript.

\section{Ethics approval and consent to participate}

The study was approved by the local ethics committee of the Medical Faculty at the University of Leipzig (approval number: 292-15-24,082,015). All patients willing to participate provide written informed consent.

\section{Consent for publication}

Not applicable.

\section{Competing interests}

The authors declare that they have no competing interests.

\section{Publisher's Note}

Springer Nature remains neutral with regard to jurisdictional claims in published maps and institutional affiliations.

Received: 31 January 2017 Accepted: 26 June 2017

Published online: 12 July 2017

\section{References}

1. Kumar SK, Rajkumar SV, Dispenzieri A, Lacy MQ, Hayman SR, Buadi FK, et al. Improved survival in multiple myeloma and the impact of novel therapies. Blood. 2008:111:2516-20.

2. Pulte $\mathrm{D}$, Gondos $\mathrm{A}$, Brenner $\mathrm{H}$. Trends in survival after diagnosis with hematologic malignancy in adolescence or young adulthood in the United States, 1981-2005. Cancer. 2009;115:4973-9. doi:10.1002/cncr.24548.

3. Verdecchia A, Francisci S, Brenner H, Gatta G, Micheli A, Mangone L, Kunkler I. Recent cancer survival in Europe: a 2000-02 period analysis of EUROCARE-4 data. Lancet Oncol. 2007;8:784-96. doi:10.1016/S14702045(07)70246-2.

4. Rodriguez-Abreu D, Bordoni A, Zucca E. Epidemiology of hematological malignancies. Ann Oncol. 2007;18(Suppl 1):i3-8. doi:10.1093/annonc/ mdl443.

5. Siegel R, DeSantis C, Virgo K, Stein K, Mariotto A, Smith T, et al. Cancer treatment and survivorship statistics, 2012. CA Cancer J Clin. 2012;62:220-41. doi:10.3322/caac.21149.

6. Efficace F, Novik A, Vignetti M, Mandelli F, Cleeland CS. Health-related quality of life and symptom assessment in clinical research of patients with hematologic malignancies: where are we now and where do we go from here? Haematologica. 2007;92:1596-8. doi:10.3324/haematol. 11710.

7. Stephens JM, Gramegna P, Laskin B, Botteman MF, Pashos CL. Chronic lymphocytic leukemia: economic burden and quality of life: literature review. Am J Ther. 2005;12:460-6.

8. Johnsen AT, Tholstrup D, Petersen MA, Pedersen L, Groenvold M. Health related quality of life in a nationally representative sample of haematological patients. Eur J Haematol. 2009;83:139-48. doi:10.1111/j.1600-0609.2009.01250.x.

9. de la Puente P, Muz B, Azab F, Luderer M, Azab AK. Molecularly targeted therapies in multiple myeloma. Leuk Res Treatment. 2014;2014:976567. doi: 10.1155/2014/976567.

10. Molica S. Quality of life in chronic lymphocytic leukemia: a neglected issue. Leuk Lymphoma. 2005;46:1709-14. doi:10.1080/10428190500244183.

11. Byrd JC, Mrózek K, Dodge RK, Carroll AJ, Edwards CG, Arthur DC, et al. Pretreatment cytogenetic abnormalities are predictive of induction success, cumulative incidence of relapse, and overall survival in adult patients with de novo acute myeloid leukemia: results from Cancer and Leukemia Group B (CALGB 8461). Blood. 2002;100:4325-36. doi:10.1182/blood-2002-03-0772.

12. van Leeuwen, Flora E, Klokman WJ, van't Veer, Mars B, Hagenbeek A, ADG K, $U A O V$, et al. Long-term risk of second malignancy in survivors of Hodgkin's disease treated during adolescence or young adulthood. J Clin Oncol. 2000; 18:487.

13. Ng AK, Bernardo MVP, Weller E, Backstrand K, Silver B, Marcus KC, et al. Second malignancy after Hodgkin disease treated with radiation therapy with or without chemotherapy: long-term risks and risk factors. Blood. 2002; 100:1989-96 doi:10.1182/blood-2002-02-0634

14. Copelan EA. Hematopoietic stem-cell transplantation. N Engl J Med. 2006; 354:1813-26.

15. Carter A, Robison LL, Francisco L, Smith D, Grant M, Baker KS, et al. Prevalence of conception and pregnancy outcomes after hematopoietic cell transplantation: report from the bone marrow transplant survivor study. Bone Marrow Transplant. 2006:37:1023-9. doi:10.1038/sj.bmt.1705364.

16. Borgmann-Staudt A, Rendtorff R, Reinmuth S, Hohmann C, Keil T, Schuster FR, et al. Fertility after allogeneic haematopoietic stem cell transplantation in childhood and adolescence. Bone Marrow Transplant. 2012;47:271-6. doi: 10.1038/bmt.2011.78.

17. Syrjala KL, Artherholt SB, Kurland BF, Langer SL, Roth-Roemer S, Elrod JB, Dikmen S. Prospective neurocognitive function over 5 years after allogeneic hematopoietic cell transplantation for cancer survivors compared with matched controls at 5 years. J Clin Oncol. 2011;29:2397-404. doi:10.1200/ JCO.2010.33.9119.

18. Syrjala KL, Langer SL, Abrams JR, Storer BE, Martin PJ. Late effects of hematopoietic cell transplantation among 10-year adult survivors compared with case-matched controls. J Clin Oncol. 2005;23:6596-606. doi:10.1200/ JCO.2005.12.674

19. Syrjala KL, Langer SL, Abrams JR, Storer B, Sanders JE, Flowers MED, Martin PJ. Recovery and long-term function after hematopoietic cell transplantation for leukemia or lymphoma. JAMA. 2004;291:2335-43.

20. Baker KS, Gurney JG, Ness KK, Bhatia R, Forman SJ, Francisco L, et al. Late effects in survivors of chronic myeloid leukemia treated with hematopoietic cell transplantation: results from the bone marrow transplant survivor study. Blood. 2004;104:1898-906. doi:10.1182/blood-2004-03-1010.

21. Short PF, Vasey JJ, Tunceli K. Employment pathways in a large cohort of adult cancer survivors. Cancer. 2005;103:1292-301. doi:10.1002/cncr. 20912.

22. Mols F, Vingerhoets AJJM, Coebergh JW, Vreugdenhil G, Aaronson NK, Lybeert MLM, van de Poll-Franse LV. Better quality of life among 10-15 year survivors of Hodgkin's lymphoma compared to 5-9 year survivors: a population-based study. Eur J Cancer. 2006;42:2794-801. doi:10.1016/j.ejca. 2006.08.006.

23. Mols F, Aaronson NK, Vingerhoets AJJM, Coebergh JW, Vreugdenhil G, Lybeert MLM, van de Poll-Franse LV. Quality of life among long-term non-Hodgkin lymphoma survivors: a population-based study. Cancer. 2007; 109:1659-67. doi:10.1002/cncr.22581.

24. Smith SK, Zimmerman S, Williams CS, Zebrack BJ. Health status and quality of life among non-Hodgkin lymphoma survivors. Cancer. 2009:115:3312-23. doi:10.1002/cncr.24391

25. Rüffer JU, Flechtner $H$, Tralls $P$, Josting $A$, Sieber $M$, Lathan B, Diehl V. Fatigue in long-term survivors of Hodgkin's lymphoma; a report from the German Hodgkin Lymphoma Study Group (GHSG). Eur J Cancer. 2003;39: 2179-86. doi:10.1016/S0959-8049(03)00545-8. 
26. Miltényi Z, Magyari F, Simon Z, Illés Á. Quality of life and fatigue in Hodgkin's lymphoma patients. Tumori. 2010;96:594-600.

27. Wettergren $L$, Björkholm M, Axdorph U, Bowling A, Langius-Eklöf A. Individual quality of life in long-term survivors of Hodgkin's lymphoma-a comparative study. Qual Life Res. 2003;12:545-54.

28. Haberman M, Bush N, Young K, Sullivan KM. Quality of life of adult long-term survivors of bone marrow transplantation: a qualitative analysis of narrative data. Oncol Nurs Forum. 1993;20:1545-553.

29. Zebrack B. Quality of life of long-term survivors of leukemia and lymphoma. J Psychosoc Oncol. 2000;18:39-59.

30. Lim J, Zebrack B. Social networks and quality of life for long-term survivors of leukemia and lymphoma. Support Care Cancer. 2006;14:185-92. doi:10. 1007/s00520-005-0856-x.

31. Buffart LM, Ros WJG, Chinapaw MJM, Brug J, Knol DL, Korstjens I, et al. Mediators of physical exercise for improvement in cancer survivors' quality of life. Psychooncology. 2014;23:330-8. doi:10.1002/pon.3428.

32. Knoop H, Prins JB, Moss-Morris R, Bleijenberg G. The central role of cognitive processes in the perpetuation of chronic fatigue syndrome. J Psychosom Res. 2010;68:489-94. doi:10.1016/j.jpsychores.2010.01.022

33. Groarke A, Curtis R, Kerin M. Global stress predicts both positive and negative emotional adjustment at diagnosis and post-surgery in women with breast cancer. Psychooncology. 2013;22:177-85. doi:10.1002/pon.2071.

34. Wilson IB. Linking clinical variables with health-related quality of life. A conceptual model of patient outcomes. JAMA. 1995;273:59-65. doi:10.1001/ jama.273.1.59.

35. LimeSurvey Project Team / Carsten Schmitz. LimeSurvey: an open source survey tool. Germany: LimeSurvey Project Hamburg; 2015.

36. Esser P, Kuba K, Mehnert A, Schwinn A, Schirmer L, Schulz-Kindermann F, et al. Investigating the temporal course, relevance and risk factors of fatigue over 5 years: a prospective study among patients receiving allogeneic HSCT. Bone Marrow Transplant. 2017; doi:10.1038/bmt.2016.344.

37. Aaronson NK, Ahmedzai S, Bergman B, Bullinger M, Cull A, Duez NJ, et al. The European Organization for Research and Treatment of Cancer QLQ-C30 a quality-of-life instrument for use in international clinical trials in oncology. J Natl Cancer Inst. 1993;85:365-76.

38. Hinz A, Singer S, Brähler E. European reference values for the quality of life questionnaire EORTC QLQ-C30: results of a German investigation and a summarizing analysis of six European general population normative studies. Acta Oncol. 2014;53:958-65. doi:10.3109/0284186X.2013.879998.

39. Faul F, Erdfelder E, Lang A, Buchner A. G* Power 3: a flexible statistical power analysis program for the social, behavioral, and biomedical sciences. Behav Res Methods. 2007;39:175-91.

40. Faul F, Erdfelder E, Buchner A, Lang A. Statistical power analyses using G*Power 3.1: tests for correlation and regression analyses. Behav Res Methods. 2009:41:1149-60. doi:10.3758/BRM.41.4.1149.

41. Daig I, Herschbach P, Lehmann A, Knoll N, Decker O. Gender and age differences in domain-specific life satisfaction and the impact of depressive and anxiety symptoms: a general population survey from Germany. Qual Life Res. 2009:18:669-78. doi:10.1007/s11136-009-9481-3.

42. Kocalevent R, Hinz A, Brähler E. Standardization of the depression screener patient health questionnaire (PHQ-9) in the general population. Gen Hosp Psychiatry. 2013;35:551-5. doi:10.1016/j.genhosppsych.2013.04.006.

43. Löwe B, Decker O, Müller S, Brähler E, Schellberg D, Herzog W, Herzberg PY, Validation and standardization of the Generalized Anxiety Disorder Screener (GAD-7) in the general population. Med Care. 2008:46:266-74.

44. Fydrich T, Sommer G, Tydecks S, Brähler E. Fragebogen zur sozialen unterstützung (F-SozU): Normierung der Kurzform (K-14) [Social Support Questionnaire (F-SozU): standardization of short form (K-14)]. Z Med Psychol. 2009:18:43-8

45. Kliem S, Job A, Kröger C, Bodenmann G, Stöbel-Richter Y, Hahlweg K, Brähler E. Entwicklung und Normierung einer Kurzform des Partnerschaftsfragebogens (PFB-K) an einer repräsentativen deutschen Stichprobe [Development and standardization of a short form of the Partnership Questionnaire (PFB-K) on a representative German sample]. Z Klin Psychol Psychother. 2012;41:81-9. doi:10.1026/1616-3443/a000135.

46. Jocham $H$, Dassen $T$, Widdershoven $G$, Halfens R. Reliability and validity of the EORTC QLQ-C30 in palliative care cancer patients. Cent Eur J Med. 2009; 4:348-57. doi:10.2478/s11536-009-0032-7.

47. Henrich G, Herschbach P. Questions on life satisfaction (FLZM) - a short questionnaire for assessing subjective quality of life. Eur J Psychol Assess. 2000;16:150-9. doi:10.1027//1015-5759.16.3.150.
48. Watson D, Clark LA, Tellegen A. Development and validation of brief measures of positive and negative affect: the PANAS scales. J Pers Soc Psychol. 1988;54:1063.

49. Krohne HW, Egloff B, Kohlmann C, Tausch A. Untersuchungen mit einer deutschen version der "Positive and Negative Affect Schedule" (PANAS) [investigations with a German version of the Positive and Negative Affect Schedule (PANAS)]. Diagnostica. 1996;42:139-56.

50. Spitzer RL, Kroenke K, JBW W, Patient Health Questionnaire Primary Care Study Group. Validation and utility of a self-report version of PRIME-MD: the PHQ primary care study. JAMA. 1999;282:1737-44.

51. Gräfe K, Zipfel S, Herzog W, Löwe B. Screening psychischer Störungen mit dem "Gesundheitsfragebogen für Patienten (PHQ-D)" [Screening for psychiatric disorders with the Patient Health Questionnaire (PHQ). Results from the German validation study]. Diagnostica. 2004;50:171-81. doi:10. 1026/0012-1924.50.4.171.

52. Roth AJ, Kornblith AB, Batel-Copel L, Peabody E, Scher HI, Holland JC. Rapid screening for psychologic distress in men with prostate carcinoma. Cancer. 1998;82:1904-8.

53. Mehnert A, Müller D, Lehmann C, Koch U. Die deutsche version des NCCN distress-thermometers [the German version of the NCCN distress thermometer: validation of a screening instrument for assessment of psychosocial distress in cancer patients]. Z Klin Psychol Psychiatr Psychother. 2006;54:213-23. doi:10.1024/1661-4747.54.3.213.

54. Herschbach P, Berg P, Dankert A, Duran G, Engst-Hastreiter U, Waadt S, et al Fear of progression in chronic diseases: psychometric properties of the Fear of Progression Questionnaire. J Psychosom Res. 2005;58:505-11. doi:10.1016/ j.jpsychores.2005.02.007.

55. Mendoza TR, Wang XS, Cleeland CS, Morrissey M, Johnson BA, Wendt JK, Huber SL. The rapid assessment of fatigue severity in cancer patients. Cancer. 1999:85:1186-96.

56. Radbruch L, Sabatowski R, Elsner F, Everts J, Mendoza T, Cleeland C. Validation of the German version of the brief fatigue inventory. J Pain Symptom Manag. 2003;25:449-58. doi:10.1016/S0885-3924(03)00073-3.

57. Schreurs PJ, Van de Willige G, Brosschot JF, Tellegen B, Graus GM. De Utrechtse coping lijst: UCL [the Utrecht coping list: UCL]. Lisse: Swets en Zeitlinger; 1993.

58. Neugebauer U, Latscha K. Bewältigung belastender Ereignisse bei Polizeibeamten [Coping with stressful events among police officials]. Polizei \& Wissenschaft. 2009;3:55-61.

59. Neugebauer U, Wilbert J. Zum Zusammenhang zwischen Bewältigungsstil und burnout-Symptomen bei Lehrkräften der Förderschule Lernen The link between coping style and burnout among special education teachers for children with learning difficulties]. Empirische Sonderpädagogik. 2010;2:69-82.

60. Bond FW, Hayes SC, Baer RA, Carpenter KM, Guenole N, Orcutt HK, et al. Preliminary psychometric properties of the Acceptance and Action Questionnaire-Il: a revised measure of psychological inflexibility and experiential avoidance. Behav Ther. 2011;42:676-88. doi:10.1016/j.beth. 2011.03.007.

61. Hoyer J, Gloster AT. Psychologische Flexibilität messen: Der Fragebogen zu Akzeptanz und Handeln II [Measuring psychological flexibility: the AAQ II]. Verhaltenstherapie. 2013;23:42-4. doi:10.1159/000347040.

62. Wiebe DJ, Berg CA, Palmer DL, Korbel C, Beveridge RM, Lindsay R, Donaldson D. Illness and the self: examining adjustment among adolescents with diabetes. Washington: Paper presented: Society of Behavioral Medicine; 2002

63. Helgeson VS. Survivor centrality among breast cancer survivors: implications for well-being. Psychooncology. 2011;20:517-24. doi:10. 1002/pon.1750.

64. Helgeson VS, Novak SA. Illness centrality and well-being among male and female early adolescents with diabetes. J Pediatr Psychol. 2007;32:260-72. doi:10.1093/jpepsy/jsl018.

65. Wallston KA, Wallston BS, DeVellis R. Development of the multidimensional health locus of control (MHLC) scales. Health Educ Behav. 1978;6:160-70.

66. Dlugosch GE, Krieger W. Fragebogen zur Erfassung des Gesundheitsverhaltens (FEG): Swetz and Zeitlinger; 1995.

67. Schulze A, Lampert T. Bundes-Gesundheitssurvey: soziale Unterschiede im Rauchverhalten und in der Passivrauchbelastung in Deutschland [Report of the Federal Health Monitoring of Germany: social differences in smoking behavior and passive smoke exposure in Germany]. Berlin: Robert Koch-Institut; 2006. 
68. Cimprich B, Visovatti M, Ronis DL. The attentional function index-a self-report cognitive measure. Psychooncology. 2011;20:194-202. doi:10.1002/pon.1729.

69. Fydrich T, Sommer G, Brähler E. Fragebogen zur Sozialen Unterstützung: F-SozU [Questionnaire on social support: F-SozU]. Göttingen: HOGREFE; 2007.

70. Boyes A, Girgis A, Lecathelinais C. Brief assessment of adult cancer patients' perceived needs: development and validation of the 34-item Supportive Care Needs Survey (SCNS-SF34). J Eval Clin Pract. 2009;15:602-6. doi:10. 1111/j.1365-2753.2008.01057.X.

71. Lehmann C, Koch U, Mehnert A. Psychometric properties of the German version of the Short-Form Supportive Care Needs Survey Questionnaire (SCNS-SF34-G). Support Care Cancer. 2012;20:2415-24. doi:10.1007/s00520011-1351-1.

72. Tuomi K, Ilmarinen J, Jahkola A, Katajarinne L, Tulkki A. Work ability index. Helsinki: Institute of Occupational Health Helsinki; 1994.

73. WAl-Netzwerk Deutschland [WAI Network Gemany]. Wie steht es um Ihre Arbeitsfähigkeit? [How is your working ability?]. http://www. arbeitsfaehigkeit.uni-wuppertal.de/picture/upload/file/WAI-Kurzversion_ mit\%20Auswertung_2015.pdf. Accessed 17 Nov 2016.

74. Hahlweg K. Fragebogen zur Partnerschaftsdiagnostik (FPD) [Questionnaire on partnership]. Göttingen: HOGREFE; 1996.

75. Geue K, Richter D, Schmidt R, Sender A, Siedentopf F, Brähler E, StöbelRichter $Y$. The desire for children and fertility issues among young German cancer survivors. J Adolesc Health. 2014;54:527-35. doi:10.1016/j.jadohealth. 2013.10.005.

76. Bayliss EA, Ellis JL, Steiner JF. Subjective assessments of comorbidity correlate with quality of life health outcomes: initial validation of a comorbidity assessment instrument. Health Qual Life Outcomes. 2005;3:1.

\section{Submit your next manuscript to BioMed Central and we will help you at every step:}

- We accept pre-submission inquiries

- Our selector tool helps you to find the most relevant journal

- We provide round the clock customer support

- Convenient online submission

- Thorough peer review

- Inclusion in PubMed and all major indexing services

- Maximum visibility for your research

Submit your manuscript at www.biomedcentral.com/submit

C) Biomed Central 